\title{
Roles of Ascospores and Arthroconidia of Xylogone ganodermophthora in Development of Yellow Rot in Cultivated Mushroom, Ganoderma lucidum
}

\author{
Hyo-Jung Kang ${ }^{1,2 *}$, Who-Bong Chang ${ }^{2}$, Sung-Hwan Yun ${ }^{3}$ and Yin-Won Lee ${ }^{4}$ \\ ${ }^{1}$ Watermelon Research Institute, Chungcheongbuk-do Agricultural Research and Extension Services, Eumsung 369-824, Korea \\ ${ }^{2}$ Enviroment-friendly Agriculture Research Division, Chungcheongbuk-do Agricultural Research and Extension Services, Cheongwon \\ 363-883, Korea \\ ${ }^{3}$ Department of Medical Biotechnology, Soonchunhyang University, Asan 336-745, Korea \\ ${ }^{4}$ Department of Agricultural Biotechnology and Center for Fungal Pathogenesis, Seoul National University, Seoul 151-921, Korea \\ (Received on February 12, 2011; Accepted on May 15, 2011)
}

Xylogone ganodermophthora, an ascomycetous fungus, is known to cause yellow rot in the cultivated mushroom Ganoderma lucidum. In this study, we investigated the dissemination of this fungal pathogen in $G$ lucidum grown in cultivation houses. To determine the role of ascospores produced by $X$. ganodermophthora in disease development, we constructed a green fluorescent proteinlabeled transgenic strain. This $X$. ganodermophthora strain produced a number of ascomata in the tissues of oak logs on which G. lucidum had been grown and on the mushroom fruit bodies. However, the ascospores released from the ascomata were not able to germinate on water agar or potato dextrose agar. Moreover, less than $0.1 \%$ of the ascospores showed green fluorescence, indicating that most ascospores of $X$. ganodermophthora were not viable. To determine the manner in which $X$. ganodermophthora disseminates, diseased oak logs were either buried in isolated soil beds as soil-borne inocula or placed around soil beds as air-borne inocula. In addition, culture bottles in which $\boldsymbol{G}$ lucidum mycelia had been grown were placed on each floor of a five-floor shelf near $X$. ganodermophthora inocula. One year after cultivation, yellow rot occurred in almost all of the oak logs in the soil beds, including those in beds without soilborne inocula. In contrast, none of the $G$ lucidum in the culture bottles was infected, suggesting that dissemination of $X$. ganodermophthora can occur via the cultivation soil.

Keywords : ascospore germination, disease cycle, Ganoderma lucidum, yellow rot, Xylogone ganodermophthora

Yellow rot is a fungal disease of cultivated Ganoderma lucidum P. Karst., caused by an ascomycetous fungus. For many years, the causal pathogen was misidentified as

\footnotetext{
*Corresponding author.

Phone) +82-43-220-5862, FAX) +82-43-220-5859

E-mail)pine86@korea.kr
}

Xylogone sphaerospora (anamorph: Sporendonema purpurascens) or Arthrographis cuboidea (Lee et al., 1996; Oh et al., 1998). Recently, we reported a new species, Xylogone ganodermophthora (anamorph: Scytalidium ganodermophthorum), as the causal agent of yellow rot on the basis of phylogeny, pathogenicity, and population structure (Kang et al., 2010). Yellow rot on G. lucidum is the most destructive disease in cultivation areas in Korea (Choi et al., 1996; Choi et al., 1998). The typical symptom of yellow rot is greenish yellow discoloration of inner tissue at the base of a diseased mushroom or in inner tissue of diseased oak logs on which G. lucidum has been grown. In heavily infected fields, mushroom fruit bodies are formed only on a few or on no logs. Malformation of pilei has also been observed in mushrooms grown on diseased logs (Kang et al., 2010). Previous studies have described physiological parameters for growth of $X$. ganodermophthora, such as appropriate carbon and nitrogen sources, optimum $\mathrm{pH}$ and temperature, and optimum condition for ascocarp production (Lee et al., 1996; Oh, 1996). However, ecological characteristics related to the development of yellow rot have rarely been examined. The objective of this study was to elucidate components of the yellow rot disease cycle, including ascospore germination, primary and secondary inoculum, dissemination, and overwintering.

\section{Materials and Methods}

Ascospore preparation. Mycelial plugs of $X$. ganodermophthora H55 were inoculated into sawdust media (Lee et al., 1996) and incubated at $28^{\circ} \mathrm{C}$. After 1 month, one spoonful of fungal culture was suspended in $50 \mathrm{ml}$ sterile distilled water. The solution was filtered through cheesecloth and ascocarps were collected by centrifugation at $5,000 \times g$ for $5 \mathrm{~min}$. The ascocarp solution was transferred into 1.8-ml Eppendorf tubes and centrifuged for harvest of ascospores. Using a sterile stick, ascocarps were broken in $1 \mathrm{ml}$ sterile water and added to each Eppendorf tube. The 
suspension was filtered twice through a Whatman No. 2 filter paper, and the filtrate containing ascospores was collected in a new tube. After centrifugation, the ascospore pellet was dissolved in $100 \mathrm{ml}$ sterile water and stored at $4^{\circ} \mathrm{C}$.

Ascospore germination test. To determine a possible primary inoculum for yellow rot on G. lucidum, several propagules of $X$. ganodermophthora were tested, including sexual fruit bodies (ascocarps), sexual spores (ascospores), asexual spores (arthroconidia), and mycelia found in the tissue of infected oak logs and fruiting bodies of G. lucidum. Ten ascocarps of $X$. ganodermophthora were placed on water agar (WA) and incubated at $28^{\circ} \mathrm{C}$ in the dark. Mycelial growth was examined for each ascocarp until week 5. In another experiment, each of 10 ascocarps was broken and incubated under the same conditions, and mycelial growth was examined until week 5 . Ten aliquots of ascospore suspensions (approximately 10 spores/ $\mu \mathrm{l}$ ) were placed on WA and incubated under the same conditions as described above. Ascospore germination was examined until 6 months after inoculation.

To increase the germination rate of ascospores, various

Table 1. Effect of chemical compounds on the germination of $X$. ganodermophthora ascospores

\begin{tabular}{lccc}
\hline \hline \multicolumn{1}{c}{ Treatment } & $\begin{array}{c}\text { Conc. } \\
(\mathrm{M})\end{array}$ & $\begin{array}{c}\text { No. of ascospores } \\
\text { treated per well }\end{array}$ & Germination $^{\mathrm{b}}$ \\
\hline${\mathrm{PDA}+\mathrm{GE}^{\mathrm{c}}}^{\mathrm{a}}$ & 100 & $0 / 1$ \\
\hline${\mathrm{PDA}+\mathrm{EO}^{\mathrm{d}}}^{\mathrm{n}}$ & & 100 & $0 / 1$ \\
$\mathrm{D}(+)-G l u c o s e$ & $1-10^{-23}$ & 100 & $15 / 24$ \\
BABA & $1-10^{-23}$ & 100 & $0 / 24$ \\
L-Glutamic acid & $1-10^{-23}$ & 100 & $0 / 24$ \\
SA & $1-10^{-23}$ & 100 & $0 / 24$ \\
Desoxycholic acid & $1-10^{-23}$ & 100 & $0 / 24$ \\
\hline $\mathrm{D}(+)-G l u c o s e$ & 1 & $150-170$ & $5 / 5$ \\
& 2 & $150-170$ & $1 / 5$ \\
& 3 & $150-170$ & $0 / 5$ \\
& 4 & $150-170$ & $0 / 5$ \\
D. W. & 5 & $150-170$ & $0 / 5$ \\
\hline
\end{tabular}

${ }^{a}$ Cell culture plates $(24$ wells, well size $15 \mathrm{~mm}$ deep, $15 \mathrm{~mm}$ high, Costar) were used. One mycelial plug of G. lucidum grown on PDA was placed in a well with $1 \mathrm{ml}$ glucose or other aqueous solution. Ascospore suspensions in sterile distilled water (150-170 spores/10 $\mu \mathrm{l})$ were added to mycelia plugs in separate wells. BABA, DL- $\beta-$ amino-n-butyric acid; SA, sodium salt of salicylic acid.

${ }^{b}$ Number (No.) of wells in which mycelial growth of $X$. ganodermophthora was observed/No. of treated wells.

PDA + GE: Ascospores were spread on a PDA plate prepared in water extracts $(50 \mathrm{~g} / 1000 \mathrm{ml})$ of $\mathrm{G}$. lucidum fruit body.

${ }^{d}$ PDA + EO: Ascospores were spread on a PDA plate prepared in water extracts $(50 \mathrm{~g} / 1000 \mathrm{ml})$ of oak $\log$. carbon, nitrogen, and amino acid sources were added to PDA or dissolved in sterile water. Using cell culture plates $\left(\right.$ Costar $\left.^{\mathrm{TM}}\right)$, approximately 100 ascospores/well or 150-170 ascospores/well were transferred to the media and incubated at $28^{\circ} \mathrm{C}$ for 2 weeks (Table 1). The effect of UV irradiation on ascospore germination was examined in another experiment (Table 2). Five drops (100 spores/10 $\mu 1)$ of $X$. ganodermophthora ascospore suspension were put on a PDA plate. After UV exposure and incubation at $28^{\circ} \mathrm{C}$, mycelial growth of $X$. ganodermophthora was examined visually at 3-day intervals for 17 days. To examine the effect of cold treatment on germination rate, ascospore suspensions of $X$. ganodermophthora $(10$ spores $/ \mu 1)$ were stored at -20 or $-70^{\circ} \mathrm{C}$ for $0-90$ days. After storage, 1,000 ascospores were put on two PDA plates in 10 drops (100 ascospores $/ 10 \mu \mathrm{l} / \mathrm{drop}$ ) and incubated at $28^{\circ} \mathrm{C}$. Ascospore germination was determined by visually observing mycelial growth of $X$. ganodermophthora every day for 2 weeks

Table 2. Effect of UV irradiation on the germination of X. ganodermophthora ascospores.

\begin{tabular}{ccc}
\hline \hline \multirow{2}{*}{$\begin{array}{c}\text { Time exposed to } \\
\text { UV (Sec) }\end{array}$} & \multicolumn{2}{c}{ Germination $^{\mathrm{a}}$} \\
\cline { 2 - 3 } & $\begin{array}{c}\text { Short wavelength } \\
(254 \mathrm{~nm})\end{array}$ & $\begin{array}{c}\text { Long wavelength } \\
(366 \mathrm{~nm})\end{array}$ \\
\hline 0 & $1 / 5$ & $1 / 5$ \\
1 & $2 / 5$ & $4 / 5$ \\
5 & $4 / 5$ & $2 / 5$ \\
10 & $2 / 5$ & $1 / 5$ \\
15 & $1 / 5$ & $1 / 5$ \\
30 & $0 / 5$ & $1 / 5$ \\
60 & $0 / 5$ & $2 / 5$ \\
300 & $0 / 5$ & $3 / 5$ \\
\hline
\end{tabular}

${ }^{a}$ Number (No.) of drops in which mycelia growth of $X$. ganodermophthora was observed/No. of treated drops. Five drops (100 spores/10 $\mu \mathrm{l} /$ drop) of $X$. ganodermophthora ascospore suspension were put on a PDA plate. After UV exposure and incubation at $28^{\circ} \mathrm{C}$, mycelial growth of $X$. ganodermophthora was examined by eye at 3-day intervals for 17 days.

Table 3. Effect of cold treatment on the germination of $X$. ganodermophthora ascospores

\begin{tabular}{ccccccccc}
\hline \hline \multirow{2}{*}{$\begin{array}{c}\text { Temperature } \\
\left({ }^{\circ} \mathrm{C}\right)\end{array}$} & \multicolumn{7}{c}{ Stored period (day) ${ }^{\mathrm{a}}$} \\
\cline { 2 - 8 } & 0 & 3 & 5 & 10 & 20 & 30 & 60 & 90 \\
\hline-20 & 0 & 3 & 5 & 4 & 3 & 4 & 2 & 3 \\
-70 & 0 & 3 & 4 & 2 & 2 & 2 & 5 & 4 \\
\hline
\end{tabular}

${ }^{\text {a }}$ Ascospore suspensions of $X$. ganodermophthora $(10$ spores $/ \mu \mathrm{l})$ were stored at $-20^{\circ} \mathrm{C}$ or $-70{ }^{\circ} \mathrm{C}$ for $0-90$ days. After storage, 1000 ascospores were put on two PDA plates in 10 drops (100 ascospores/ $10 \mu \mathrm{l} / \mathrm{drop}$ ) and incubated at $28^{\circ} \mathrm{C}$. Ascospore germination was determined by observing mycelial growth of $X$. ganodermophthora by eye every day for 2 weeks. 
(Table 3).

Fungal transformation. Protoplasts of $X$. ganodermophthora were obtained by the protocol previously described (Lee et al., 2002) with slight modification. Mycelial plugs of the H55 strain grown on PDA for 5 days were inoculated into PD broth (Difco. $12 \mathrm{~g}$ in $50 \mathrm{ml}$ distilled water) and incubated at $28^{\circ} \mathrm{C}$ with shaking for $72 \mathrm{hr}$. Young mycelia were harvested by filtration through cheesecloth and washed with sterile water followed by sterile osmoticum stabilizer buffer (OM buffer: $1 \mathrm{M} \mathrm{NH}_{4} \mathrm{Cl}$ ). Cell wall digestion was carried out for $2-3 \mathrm{hr}$ at $30^{\circ} \mathrm{C}$ in $40 \mathrm{ml} 1 \mathrm{M} \mathrm{NH}_{4} \mathrm{Cl}$ containing $10 \mathrm{mg} / \mathrm{ml}$ Driselase (InterSpex Products, Inc. San Mateo, USA) and $2.5 \mathrm{mg} / \mathrm{ml}$ lysing enzyme (Sigma Chemical Co., St. Louis, MO, USA). This mixture was then centrifuged at $5,000 \times g$ for $5 \mathrm{~min}$. After washing twice with STC buffer, protoplasts were diluted to $1 \times 10^{8}$ protoplasts per $\mathrm{ml}$ in STC [1.2 M sorbitol, $10 \mathrm{mM}$ Tris (pH 7.5), $10 \mathrm{ml} \mathrm{CaCl}_{2}$ ]. The gene for expression of green fluorescent protein (GFP) used in this study has been described previously (Horwitz et al., 1999). Ten micrograms of a transforming plasmid DNA (pIGPAPA, $6096 \mathrm{bps)}$ ) were added into $10^{8}$ protoplasts in STC buffer. The tubes were put on ice for $10 \mathrm{~min}$, and then $1.2 \mathrm{ml}$ PEG solution (60\% polyethylene glycol: MW 3350, $\mathrm{pH} 7.5$ in $10 \mathrm{mM}$ Tris, $10 \mathrm{mM} \mathrm{CaCl}$ ) was added to each tube as $200 \mu \mathrm{l}, 200 \mu \mathrm{l}$, and $800 \mu \mathrm{l}$ aliquots. Each tube was rolled gently and incubated on ice for $15 \mathrm{~min}$. Approximately $500 \mu \mathrm{l}$ of protoplast-DNA solution was mixed with $10 \mathrm{ml}$ molten regeneration medium $(0.5 \%$ yeast extract, casein enzymatic hydrolysate, $1 \mathrm{M}$ sucrose) containing $0.8 \%$ agar and poured onto a plate. After overnight incubation, the regeneration medium plate was overlaid with $20 \mathrm{ml} 1 \%$ water agar amended with $150 \mu \mathrm{g}$ hygromycin $\mathrm{B} / \mathrm{ml}$ to a final concentration of hygromycin B of $50 \mu \mathrm{g} / \mathrm{ml}$. GFP expression was observed under a fluorescence microscope (Leica, model DMRE).

Pathogenicity test. For pathogenicity testing, mycelial plugs from a 7-day-old $X$. ganodermophthora strain $\mathrm{H} 55$ were placed on young mycelia of G. lucidum grown on PDA for 2 weeks. Ascospores or arthroconidia of $X$. ganodermophthora were prepared as described above, and the suspension $\left(1.0 \times 10^{4}\right.$ spores $\left./ \mathrm{ml}\right)$ was dropped on the mycelial mat of G. lucidum grown on PDA or sawdust medium. The ascospore suspension was also dropped or sprayed on both primordia and pili of G. lucidum grown on oak logs. To determine the onset of yellow rot in the field, 72 oak logs were buried in soil in which artificial inoculum of $X$. ganodermophthora (ascomata formed on sawdust medium) was mixed. At 2-week intervals, symptoms of yellow rot were examined by sectioning three randomly selected logs. The pathogenicity tests were carried out in three to five replicates.

Preparation of $X$. ganodermophthora inoculum for pathogen dissemination study. Xylogone ganodermophthora strain $\mathrm{H} 55$, grown on PDA at $28^{\circ} \mathrm{C}$ for 7 days, were inoculated on oak logs (Quercus sp., $\varphi=10 \mathrm{~cm}$, length $=20$ $\mathrm{cm})$. A total of 25 holes $(\varphi=8-10 \mathrm{~mm}$, depth $=2-4 \mathrm{~cm})$ were drilled in five separate lines per oak log, and mycelial plugs of H55 were placed in each of 15 holes. Then $G$. lucidum was inoculated in another 10 holes in the oak logs, as previously described for shiitake mushroom (Lentinula edodes) (Cha et al., 1989).

Greenhouse cultivation of $\boldsymbol{G}$. lucidum for disease development. Three separate soil beds $(4 \mathrm{~m}$ length $\times 2 \mathrm{~m}$ width $\times 1$ $\mathrm{m}$ depth) were prepared, each $0.5 \mathrm{~m}$ apart (Fig. 1). Twentyone or 24 oak logs were buried in each bed, and only those in the central bed were artificially inoculated with $X$. ganodermophthora as described above. Additional diseased oak logs were placed around the beds as an air-borne inoculum. For investigation of ascospore dissemination through air, mushroom culture bottles with wide openings $(\varphi=60 \mathrm{~mm}$, $700 \mathrm{ml}$ ) were used. Ganoderma lucidum were cultured on sawdust media in polypropylene culture bottles at $23-24^{\circ} \mathrm{C}$ for 4 weeks (Kim et al., 1993). The culture bottles were then placed on the soil, or on each floor of the five-floor shelf $50,90,130,140$, and $180 \mathrm{~cm}$ above the bottom of the cultivation house, with the bottle caps removed. Meanwhile, G. lucidum grown on sawdust media in the culture bottles for different periods (1-4 weeks) were placed on the soil surface in a mushroom house where yellow rot had previously occurred. One week after treatment, the culture bottles were incubated in a dew chamber (Vision Scientific Ltd.) at $28^{\circ} \mathrm{C}$ and $60-70 \%$ relative humidity for 4 weeks.

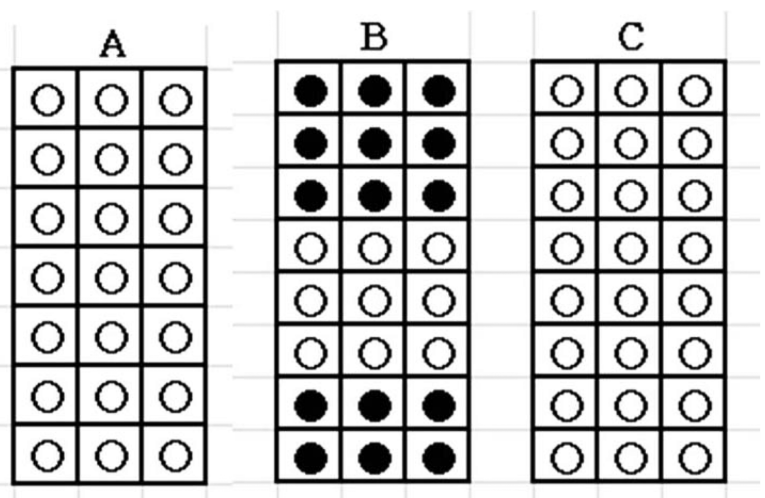

Fig. 1. Soil cultivation in a greenhouse of G. lucidum on oak logs artificially inoculated with $X$. ganodermophthora. A, C: Oak logs colonized with $G$. lucidum, but not inoculated with $X$. ganodermophthora $(\mathrm{O})$ in each soil bed, B: $\operatorname{logs}$ inoculated with $X$. ganodermophthora $(\mathbf{O})$ in the soil bed. 
Table 4. Disease severity index of yellow rot on oak wood logs in which G. lucidum had been grown

\begin{tabular}{cl}
\hline \hline Severity Index & nymptoms \\
\hline 0 & no symptoms \\
$1-10$ & slightly yellowish discoloration $(100 \%$ area $)$ without ascomata \\
$11-20$ & slightly yellowish discoloration without ascomata and brown discoloration without ascomata \\
$21-30$ & brown discoloration $(1-30 \%$ area $)$ with $1-10$ ascomata $/ \mathrm{cm}^{2}$ \\
$31-40$ & brown discoloration with $1-10$ ascomata $/ \mathrm{cm}^{2}$ and yellowish discoloration without ascomata \\
$41-50$ & brown discoloration $(100 \%$ area $)$ with $1-10$ ascomata $/ \mathrm{cm}^{2}$ \\
$51-60$ & yellowish discoloration without ascomata and brown discoloration with $1-10$ ascomata $/ \mathrm{cm}^{2}$ \\
$61-70$ & slightly greenish yellow discoloration $(100 \%$ area $)$ without ascomata \\
$71-80$ & greenish yellow discoloration $(100 \%$ area $)$ with $1-10$ ascomata $/ \mathrm{cm}^{2}$ \\
$81-90$ & greenish yellow discoloration $(100 \%$ area $)$ with some ascomata $11-99$ ascomata $/ \mathrm{cm}^{2}$ \\
$91-100$ & greenish yellow discoloration $\left(100 \%\right.$ area) with $>100$ ascomata $/ \mathrm{cm}^{2}$ \\
\hline
\end{tabular}

Disease severity was determined for each oak log using disease indices ranging from 0 to 100 (Table 4).

In another greenhouse, the following four combinations were investigated for pathogen dispersal: (1) G. lucidum grown on logs embedded in soil $+X$. ganodermophthora inoculum (diseased logs) placed on the soil surface; (2) $G$. lucidum grown on logs embedded in soil + diseased logs embedded in soil; (3) G. lucidum grown on logs placed on the soil surface + diseased logs embedded in soil; and (4) $G$. lucidum grown on logs on the soil surface without $X$. ganodermophthora inoculum. To determine any possible soil transmission, soil beds were prepared in rubber containers that were compartmented with vinyl films to minimize inflow of external air within the same greenhouse. In each rubber container, one oak log was inoculated with artificial inocula of $X$. ganodermophthora before burial in the soil along with five more $\operatorname{logs}$ not inoculated with $X$. ganodermophthora. After 5 or 8 months of cultivation, ascomata formation of $X$. ganodermophthora at the bottom of the mushroom fruiting body was examined. Greenish yellow discoloration and production of ascomata in oak logs were also examined in longitudinal sections of the logs.

\section{Results}

Ascospore germination. Of the 10 ascocarps of $X$. ganodermophthora treated, no mycelial growth was observed until week 5. Mycelia began to grow from three of the 10 broken ascomata after incubation for 7 days. Mycelial growth of $X$. ganodermophthora was not observed from the remaining seven ascocarps until week 5. No ascospores germinated until 6 months after inoculation from the 10 aliquots of ascospore suspension.

At first, none of the ascospores released from the ascocarps germinated on WA or PDA. When treated with various nutrient sources, cold, or UV irradiation, no significant increase in ascospore germination was observed, except with glucose (Tables 1-3). To determine if ascospores can germinate in soil, $300 \mu \mathrm{l}$ of spore suspension containing more than 9,000 ascospores was scattered evenly on the sterilized soil surface in a glass bottle containing G. lucidum culture on sawdust media. Three months after incubation, abundant ascomata and arthroconidia were observed on $G$. lucidum mycelia. In addition, the density of ascospores did not affect their germination rate (data not shown).

Spore viability. The fungus was transformed using a plasmid (pIGPAPA) carrying a green fluorescent protein (GFP) gene. One transformant (XST-4) exhibited distinct green fluorescence in mycelia when viewed under a fluorescence microscope (Fig. 2). However, only one of approximately 1,000 ascospores (less than $0.1 \%$ ) examined showed green fluorescence (Fig. 2).

Mycelial tips growing from broken ascocarps were transferred to PDA and incubated at $28^{\circ} \mathrm{C}$ in the dark. Abundant arthroconidia were produced on the surface of the culture. More than $70 \%$ of arthroconidia germinated on WA at $28^{\circ} \mathrm{C}$ for $72 \mathrm{hr}$ in the dark. To determine the viability in dry conditions, arthroconidia were air-dried and kept at $28^{\circ} \mathrm{C}$ in the dark; after 30 days, no arthroconidia had germinated. In the diseased logs and fruiting bodies, arthroconidia were not seen under a light microscope. Therefore, arthroconidia may not play a major role as a primary inoculum.

Pathogenicity and primary infection. When suspensions of arthroconidia, ascospores, or mycelial plugs of $X$. ganodermophthora were applied to the surface of mycelia of $G$. lucidum grown on PDA, only the arthroconidial suspension and mycelial plugs initiated infection. When these were applied on the surface of mycelia of G. lucidum growing on oak logs, the same result occurred. No infection with $X$. ganodermophthora occurred when arthroconidia or ascospores were inoculated on mushroom primordia (Table 5). However, the mushroom fruiting body did not regenerate when 

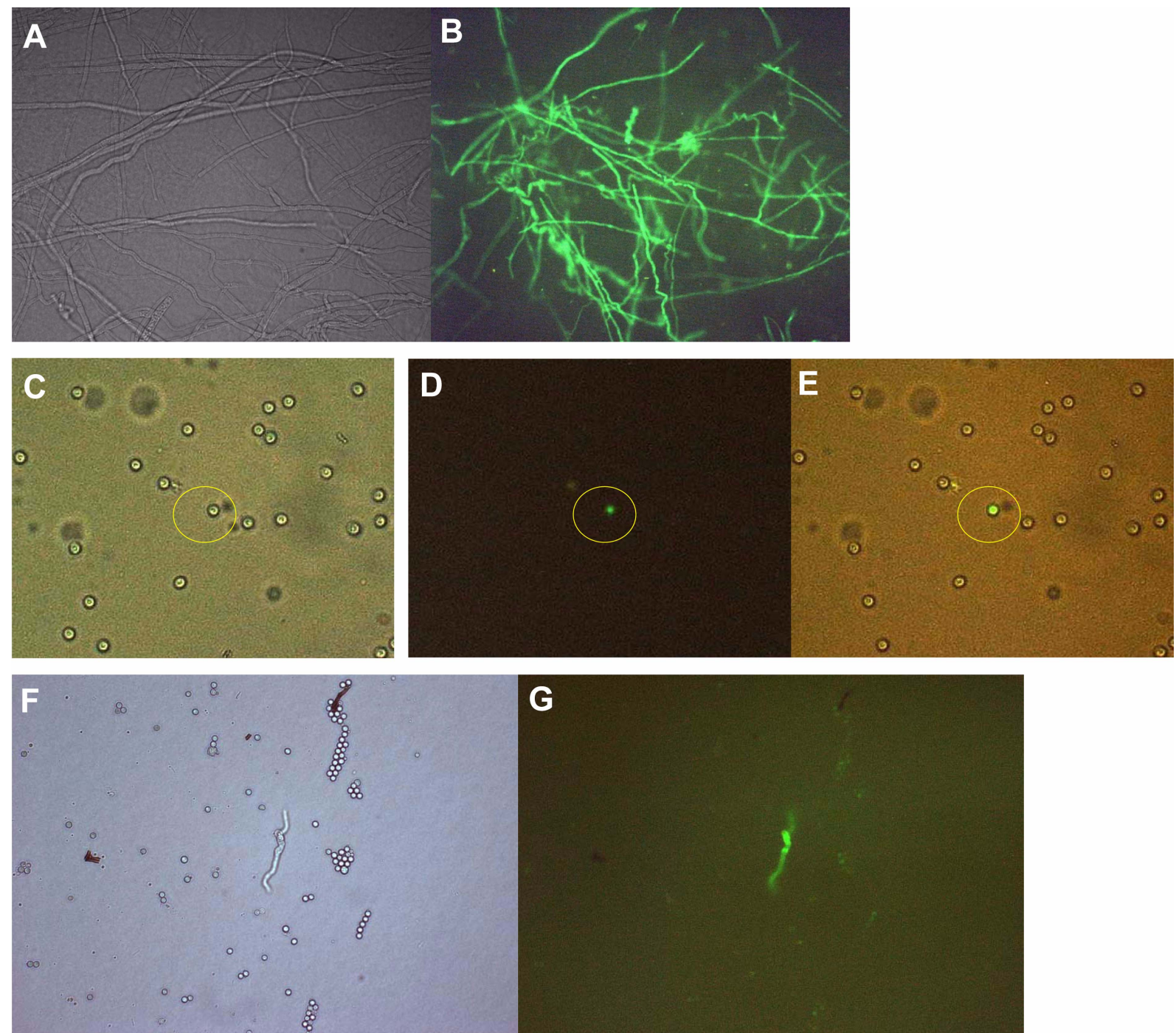

Fig. 2. GFP expression in X. ganodermophthora. (A) Mycelia of a wild-type strain (H55) of X. ganodermophthora under a light microscope, (B) mycelia of GFP-labeled X. ganodermophthora XST-4 strain under a fluorescence microscope. (C) Ascospores of $X$. ganodermophthora XST-4 strain under a light microscope, (D) under a fluorescence microscope, and (E) a superimposed image. A germinating ascospore of the GFP-labeled X. ganodermophthora XST-4 strain under a light microscope (F) and a fluorescence microscope $(\mathrm{G})$.

its cut surface was inoculated with arthroconidia after harvest (Fig. 3); lesions did not develop further.

In the field, primary infection was observed during the mycelial growth stage of G. lucidum. Early typical symptoms appeared about 1 month after inoculation with $G$. lucidum on sterilized oak logs (Fig. 4). The yellow rot symptoms observed in the farms might result from infection by ascospores of $X$. ganodermophthora, which occurred in the course of inoculation of G. lucidum. When oak logs colonized by G. lucidum were placed on the soil surface contaminated with $X$. ganodermophthora, yellow rot symptoms appeared 5 months after treatment. When oak logs of G. lucidum were buried in the soil along with artificial inoculum (ascocarps cultured on sawdust medium) of $X$. ganodermophthora, the typical yellow rot symptoms were observed 2 months after treatment. Thus, the first infection of oak logs in fields that have never previously been contaminated with $X$. ganodermophthora may occur in early March when mycelial growth of G. lucidum begins.

Secondary infection. In the greenhouse experiment, one oak log was inoculated with artificial inocula of $X$. ganodermophthora before burial in the soil along with five more logs not inoculated with $X$. ganodermophthora in each plot. Yellow rot occurred on the uninoculated logs neighboring the artificially inoculated log (Fig. 5). Abundant mycelia and ascocarps were produced in the basal part of G. lucidum that was newly infected as well as in tissues of artificially 
Table 5. Pathogenicity of mycelia, ascospores, and arthroconidia of $X$. ganodermophthora at various growth stages of $G$. lucidum

\begin{tabular}{lccccc}
\hline \hline X. ganodermophthora & \multicolumn{5}{c}{ G. lucidum } \\
\cline { 2 - 6 } & $\begin{array}{c}\text { Young } \\
\text { mycelia }\end{array}$ & $\begin{array}{c}\text { Mycelial } \\
\text { mat }\end{array}$ & Primordia & $\begin{array}{c}\text { Fruiting bodies } \\
\text { (stipes or pili) }\end{array}$ & $\begin{array}{c}\text { Cut surface } \\
\text { of fruiting body after harvest }\end{array}$ \\
\hline Mycelia & $5^{\mathrm{a}} / 5^{\mathrm{b}}$ & $5 / 5$ & $\mathrm{NT}^{\mathrm{c}}$ & $\mathrm{NT}$ & $\mathrm{NT}$ \\
Ascospore & $0 / 3$ & $0 / 3$ & $0 / 3$ & $0 / 3$ & $0 / 3$ \\
Arthroconidia & $5 / 5$ & $5 / 5$ & $0 / 3$ & $0 / 3$ & $\mathrm{NT}$ \\
Arthroconidia (GFP) & $3 / 3$ & $3 / 3$ & $0 / 3$ & $\mathrm{NT}$ & $3 / 3$ \\
\hline
\end{tabular}

${ }^{a}$ Number (No.) of plates in which mycelia of G. lucidum were diseased or No. of diseased primordia or fruiting bodies.

${ }^{b}$ No. of plates in which mycelia of G. lucidum were inoculated with mycelial plugs of $X$. ganodermophthora or No. of primordia or fruiting bodies inoculated with its spore suspension $\left(1.0 \times 10^{4}\right.$ spores $\left./ \mathrm{ml}\right)$.

${ }^{\circ}$ Not treated.

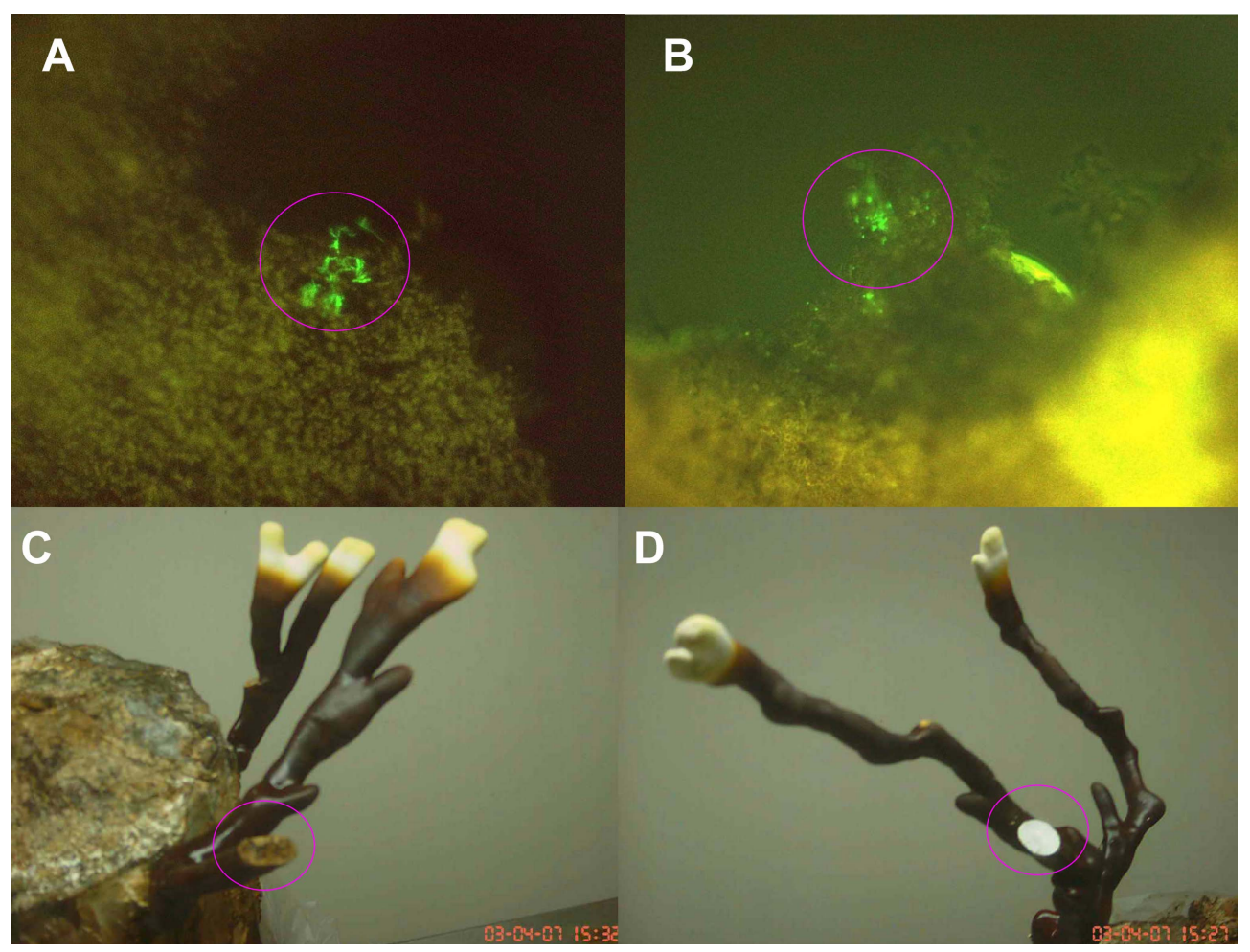

Fig. 3. Pathogenicity of $X$. ganodermophthora on the cut surface of a stipe after harvest of G. lucidum. (A), (B) Green fluorescent mycelia of $X$. ganodermophthora growing in tissue of G. lucidum (circles) $(400 \times)$. (C) Dead cut surface (circle) of a G. lucidum stipe 15 days after inoculation with arthroconidia of $X$. ganodermophthora. (D) Actively growing regenerated fruiting body from cut surface of G. lucidum which was not infected with $X$. ganodermophthora.
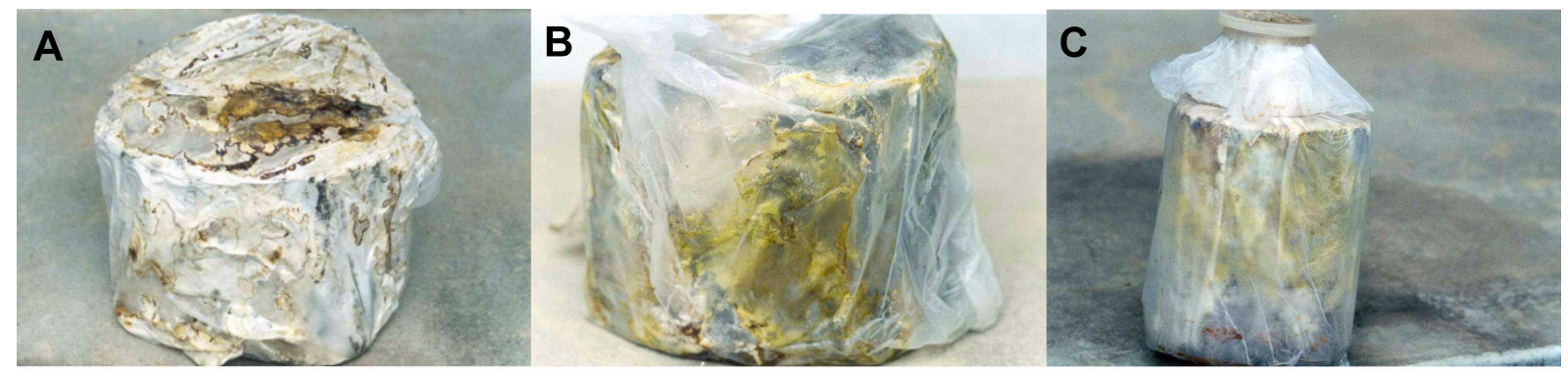

Fig. 4. Primary infection in improved short-wood cultivation. For cultivation, oak logs wrapped in high-density polyethylene bags were sterilized before inoculation of G. lucidum. (A) Healthy oak log on which a white mycelial mat of G. lucidum formed. (B) Yellow-rotinfected oak log observed during spawning and incubation of G. lucidum in farms where yellow rot had occurred for several years. (C) Oak log artificially infected with arthroconidial suspension of X. ganodermophthora after 4 weeks of incubation of G. lucidum. 

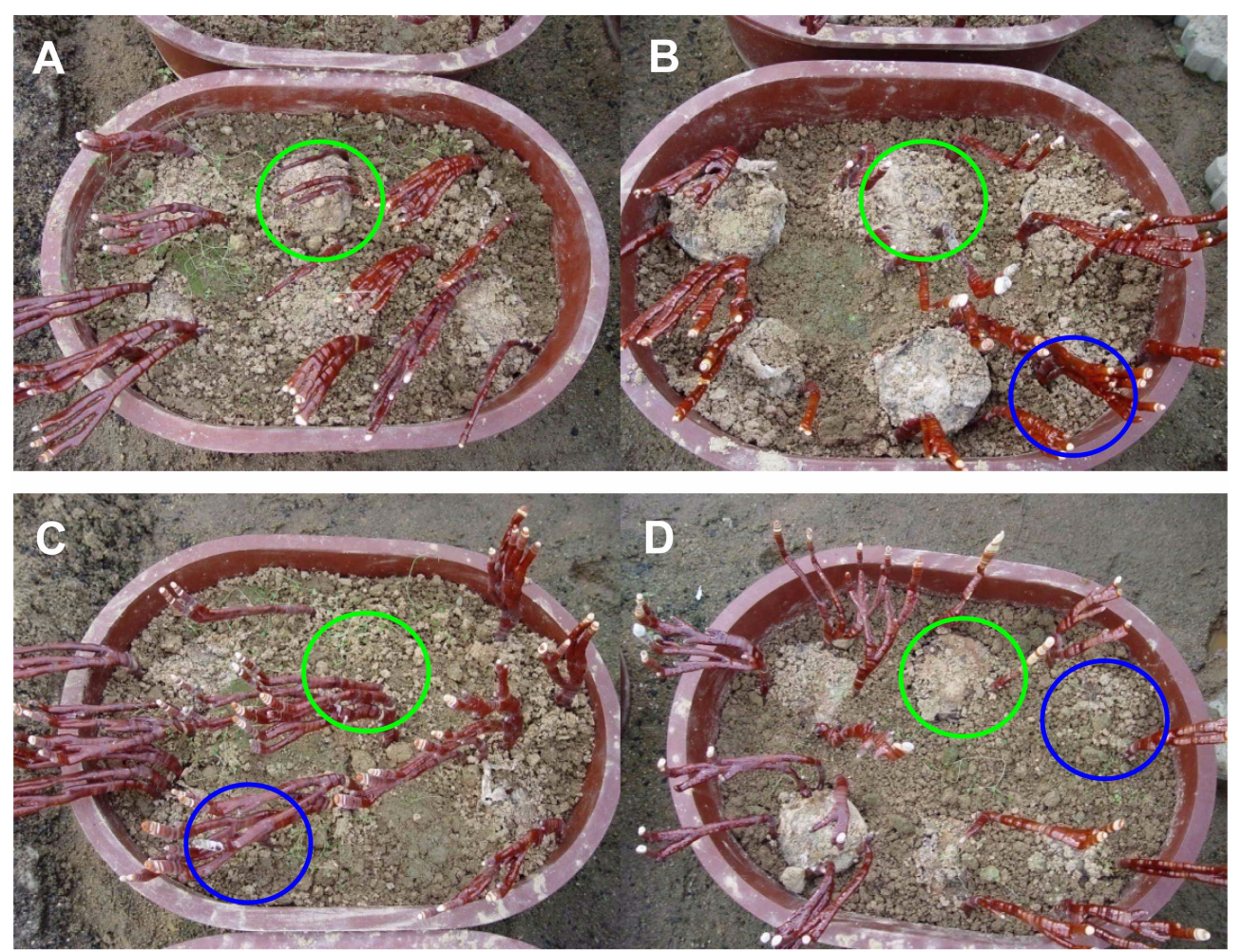

Fig. 5. Secondary infection of $X$. ganodermophthora. Fruiting bodies of G. lucidum formed on oak logs buried in soil containing one artificially inoculated-oak log per plastic container. Each $\log$ in a green circle was artificially inoculated with $X$. ganodermophthora. Newly infected oak logs buried in soil are indicated with a blue circle. For each plot, 0 of 15 (A), 8 of 17 (B), 6 of 18 (C), and 10 of 24 (D) mushroom fruiting bodies were infected with $X$. ganodermophthora 5 months after treatment.
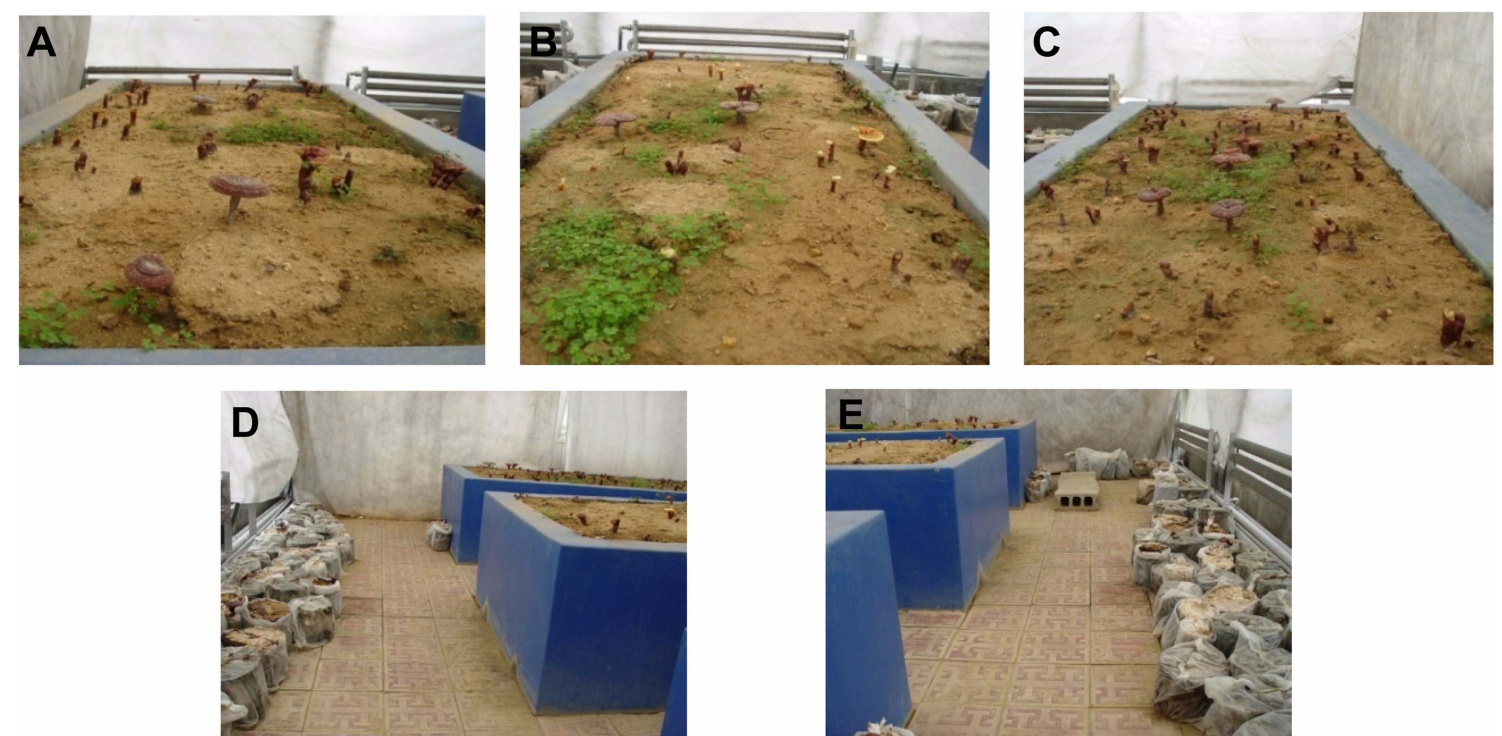

Fig. 6. Occurrence of yellow rot on G. lucidum in three isolated soil beds. (A) and (C) No inoculum in a soil bed; (B) artificially inoculated oak logs buried in the soil bed (refer to Fig. 1 for experimental design); (D) and (E) diseased oak logs placed around soil beds as air-borne inocula.

inoculated logs.

Dissemination. Because arthroconidia of $X$. ganodermo- phthora that formed on PDA were slimy whereas ascospores were not, the possibility of air-borne dissemination of $X$. ganodermophthora through ascospores was tested in the 
Table 6. Occurrence of yellow rot in bottle cultures of G. lucidum in a greenhouse contaminated with $X$. ganodermophthora

\begin{tabular}{|c|c|c|c|c|}
\hline $\begin{array}{l}\text { Culture } \\
\text { /Medium }\end{array}$ & $\mathrm{Age}^{\mathrm{a}}$ & Exposure time $^{b}$ & Location $^{c}$ & $\mathrm{YR}^{\mathrm{C}}$ \\
\hline PDA & $\mathrm{NT}^{\mathrm{i}}$ & $1,24,72 \mathrm{hr}$ & $C W\left(50-100^{e}\right)$ & No \\
\hline GL/PDA ${ }^{\mathrm{f}}$ & 1 & $2 w k$ & $\mathrm{CW}(50-100)$ & No \\
\hline \multirow[t]{2}{*}{$\mathrm{SD}^{\mathrm{g}}$} & $\mathrm{NT}^{\mathrm{i}}$ & $1,2,3,4 \mathrm{wk}$ & $\mathrm{CW}(0)$ & No \\
\hline & $1,2,3,4$ & $1,2 \mathrm{hr}$ & $\mathrm{CW}(0-100)$ & No \\
\hline \multirow[t]{2}{*}{$\mathrm{GL} / \mathrm{SD}^{\mathrm{h}}$} & $1,2,3,4$ & $1,2,3,4 \mathrm{wk}$ & $\mathrm{CW}(0-100)$ & No \\
\hline & 5 & $2 w k$ & DY (0) & No \\
\hline GL/SD & 5 & $2 w k$ & CW (in soil) & Yes $^{\mathrm{j}}$ \\
\hline
\end{tabular}

${ }^{a}$ Culture period (weeks) of G. lucidum after inoculation on PDA or sawdust medium.

${ }^{\mathrm{b}}$ Exposure time in a greenhouse contaminated with $X$. ganodermophthora after the Ganoderma culture was left open.

${ }^{\mathrm{c}}$ This experiment was conducted in two greenhouses $100 \mathrm{~km}$ apart in Chungbuk (CW: Cheongwon-gun, DY: Danyang-gun).

${ }^{\mathrm{d}}$ Occurrence of yellow rot in G. lucidum.

${ }^{\mathrm{e}}$ Distance from soil surface $(\mathrm{cm})$.

${ }_{\mathrm{f}}^{\mathrm{f}} \mathrm{GL} / \mathrm{PDA}$ : G. lucidum growing on PDA ( $\left.\varphi 87 \mathrm{~mm}\right)$.

${ }^{\mathrm{g}}$ Sawdust medium in plastic culture bottle $(\varphi 60 \mathrm{~mm})$.

${ }^{\text {h }} \mathrm{GL} / \mathrm{SD}$ : G. lucidum growing on sawdust medium in plastic culture bottle $(\varphi 60 \mathrm{~mm})$.

${ }^{\mathrm{i}}$ Not treated.

${ }^{j}$ Positive control.

Table 7. Occurrence of yellow rot after air-borne or soil-borne dissemination

\begin{tabular}{cccc}
\hline \hline G. lucidum & Inoculum & DF/TF (\%) & DL/TL (\%) \\
\hline In soil & On soil & $0 / 47(0)$ & $2 / 18(11)$ \\
In soil & In soil & $24 / 74(33)$ & $10 / 24(42)$ \\
On soil & In soil & $0 / 180(0)$ & $32 / 34(94)$ \\
On soil & No inoculum & $0 / 122(0)$ & $21 / 24(88)$ \\
\hline
\end{tabular}

${ }^{\mathrm{a}}$ Number (No.) of diseased mushroom fruiting bodies/No. of total fruiting bodies, examined 8 months after treatment.

${ }^{b}$ No. of diseased oak logs/No. of total oak logs examined 1 year after treatment.

greenhouse (Fig. 6 A-C). Petri dishes of PDA were placed in the greenhouse for 1-72 hr to trap air-borne spores of $X$. ganodermophthora. However, no pathogen colony was detected on PDA after incubation at $28^{\circ} \mathrm{C}$ for 14 days. When culture bottles in which Ganoderma mycelia were growing were left open for $1 \mathrm{hr}$ to 4 weeks in the greenhouse, yellow rot did not occur in any culture bottle (Table 6). However, yellow rot occurred in the two soil beds without inoculum of the pathogen. Yellow rot symptoms were observed on almost all oak logs in the soil beds and disease severity ranged from 4 to 100 (Fig. 7). In another greenhouse, severe yellow rot also occurred in the treatment in which oak logs were placed on the soil surface and diseased logs were buried in the soil (Table 7).

Cultivation of G. lucidum on oak logs on 3-floor cultivation shelves was conducted in naturally contaminated

\begin{tabular}{|c|c|c|}
\hline \multicolumn{3}{|c|}{ A } \\
\hline 28 & 50 & 100 \\
\hline 100 & 64 & 98 \\
\hline 70 & 28 & 70 \\
\hline 96 & 33 & 46 \\
\hline 96 & 70 & 68 \\
\hline 76 & 100 & 100 \\
\hline 4 & 14 & 44 \\
\hline
\end{tabular}

\begin{tabular}{|c|c|c|}
\hline \multicolumn{3}{|c|}{ B } \\
\hline 100 & 6 & 20 \\
\hline 22 & 39 & 14 \\
\hline 37 & 6 & 8 \\
\hline 56 & 90 & 100 \\
\hline 84 & 100 & 100 \\
\hline 4 & 100 & 100 \\
\hline 46 & 0 & 68 \\
\hline 96 & 18 & 90 \\
\hline
\end{tabular}

\begin{tabular}{|c|c|c|}
\hline \multicolumn{3}{|c|}{ C } \\
\hline 86 & 66 & 76 \\
\hline 38 & 30 & 90 \\
\hline 10 & 80 & 0 \\
\hline 86 & 38 & 100 \\
\hline 100 & 25 & 82 \\
\hline 100 & 16 & 46 \\
\hline 76 & 24 & 72 \\
\hline 28 & 100 & 86 \\
\hline
\end{tabular}

Fig. 7. Disease severity of yellow rot on oak logs on which $G$. lucidum had been grown. (A) and (C) No inoculum in a soil bed; (B) artificially inoculated oak logs buried in soil bed. Yellow-rotinfected oak logs were placed around the beds.

mushroom farms. Yellow rot did not occur in the first year of cultivation. In the second year, however, yellow rot occurred in almost all oak logs on all three floors (data not shown).

Overwintering. One year after cultivation of G. lucidum in the field (in early March), several types of propagule were collected from diseased oak logs showing yellow rot symptoms. Ascocarps and ascospores of $X$. ganodermophthora isolated from the infected tissues showed low germination on PDA (about $0.1 \%$ ), but no arthroconidia were observed.

\section{Discussion}

Most ascospores of $X$. ganodermophthora did not germinate on several different growth media or in sterile distilled water. Ascospore germination rates of some ascomycetous fungi are known to be increased by factors such as removal of self-inhibitors, abrasion of the ascospore surface, optimum density of ascospores, presence of free water, and treatment with $\mathrm{HCl}$ (Gadoury and Pearson, 1990; Fortas and Chevalier, 1992; Ramesh et al., 1993; Stone et al., 1994; Vannini et al., 1996). However the germination rate of $X$. ganodermophthora did not increase, despite the chemical and physical conditions used (Tables 1-3). Therefore, it seems that most ascospores of $X$. ganodermophthora were not viable, and the viability of ascospores was further confirmed using a GFP-labeled $X$. ganodermophthora strain. The infection time of $X$. ganodermophthora could also be inferred using the same GFP-labeled transformant. An experiment to determine the possibility of air-borne dissemination of $X$. ganodermophthora was performed by inoculating ascocarps of the GFP transformant into the soil, but we did not detect any green fluorescent ascospores in diseased logs, suggesting that air-borne dissemination of $X$. ganodermophthora might occur at a very low rate, while ascospores play an important role in primary infection. For commercial production using oak logs, G. lucidum is cultivated in or on the 
soil, not separate from the soil surface. Further investigation is needed to obtain direct evidence of air-borne dissemination of $X$. ganodermophthora using the GFP transformant.

In the greenhouse experiment, yellow rot occurred in the negative control without artificial inoculum in two isolated soil beds. This contamination might have resulted from non-sterilized oak logs and soil used in the negative control. The negative control soil beds could also have been contaminated with soil from the inoculated bed through irrigation water. However, the possibility of air-borne dissemination could not be ruled out because heavily infected oak logs had been placed on the bottom of the same greenhouse as inocula for spore trapping in the five-floor shelf cultivation.

The results from shelf cultivation of mushrooms in farms heavily contaminated with the pathogen suggest that ascospores must play a key role in primary infection of yellow rot on G. lucidum, although the germination rate of ascospores was very low $(<0.1 \%)$. In addition, arthroconidia of $X$. ganodermophthora was able to significantly inhibit mycelial growth of G. lucidum on oak logs over 8 weeks, but its inhibitory effect was greatly reduced (Kang et al., 2010). This implies that protection against early infection with this disease would reduce yield loss of G. lucidum.

Air-borne spores of $X$. ganodermophthora were not trapped on the various media or on Ganoderma mycelia. However, data obtained from the greenhouse experiment using mushroom shelf cultivation indicated that $X$. ganodermophthora could be disseminated in the air. The other set of experiments performed in the greenhouses confirmed dispersal of $X$. ganodermophthora through soil or irrigation water because inflow of external air between individual plots was minimized.

On the basis of the study results, we propose a putative disease cycle for yellow rot on G. lucidum caused by $X$. ganodermophthora. Yellow rot pathogen overwinters as ascocarps and/or mycelia mostly in tissues of diseased logs on which G. lucidum had been grown, or inside a diseased fruiting body of G. lucidum; it also overwinters as ascocarps and mycelia in the soil. In spring, ascospores arrive at the inoculum (spawn) of G. lucidum, possibly by wind, and infect growing young mycelia of the mushroom. In the soil, overwintered ascocarps, ascospores, and mycelia of $X$. ganodermophthora directly infect young mycelia of $G$. lucidum, which colonize the oak logs. The $X$. ganodermophthora continues to grow in the tissue of oak logs where G. lucidum has already been colonized. Abundant arthroconidia produced mainly under the bark of oak logs and basal parts of the mushroom fruiting body can be dispersed to other uninfected logs by irrigation water, tools, insects, or farmers. Ascocarps are produced in the tissues of infected logs and mushroom fruiting bodies 2 to 3 months after infection. They survive in the tissue of oak logs and mushroom fruiting bodies for 1 to 3 years or more. After decay of the diseased logs and mushroom fruiting bodies, the ascocarps survive for several years in the decayed tissue in the soil. They may be transmitted over long distances (several tens to hundreds of kilometers) by attaching to the facilities used for cultivation of G. lucidum, and begin another round of the disease cycle.

\section{Acknowledgements}

This research was supported by a grant from "Cooperative Research Program for Agriculture Science \& Technology Development (Project No. 007281201003)" Rural Development Administration, Republic of Korea, and a grant from the Korea Institute of Planning and Evaluation for Technology of Food, Agriculture, Forestry and Fisheries (No. 309015-04). Y-WL was supported by the National Research Foundation of Korea (NRF) grant by the Korea government (MEST) (2009-0063350).

\section{References}

Cha, D. Y. You, C. H. and Kim, G. P. 1989. Shiitake mushroom (Lentinula edodes). In: Recent technology in edible mushroom cultivation, eds. by Cha, D. Y., You, C. H. and Kim, G. P., pp. 268-333. Nongjinhoe. Suwon, Korea. (In Korean)

Choi, G. J., Cho, K. Y., Lee, J. K., Kim, B. S. and Park, J. S. 1996. Studies on the management of a fungal disease of Ganoderma lucidum(II). $81 \mathrm{pp}$. Research report of the ministry of science and technology, Korea. (In Korean)

Choi, G. J., Lee, J. K., Woo, S. H. and Cho, G. Y. 1998. Selection of effective fungicides against Xylogone sphaerospora, a fungal pathogen of cultivated mushroom, Ganoderma lucidum. Kor. J. Plant Pathol. 14:491-495. (In Korean)

Fortas, Z. and Chevalier, G. 1992. Characteristics of ascospore germination of Terfezia arenaria (Moris) Trappe originating from Algeria. Cryptogamie Mycologie 13:21-29.

Gadoury, D. M. and Pearson, R. C. 1990. Germination of ascospores and infection of Vitis by Uncinula necator. Phytopathology 80:1198-1203.

Horwitz B. A., Sharon, A., Lu, S.-W., Ritter, V., Sandrock, T. M., Yoder, O. C. and Turgeon, B. G. 1999. A G protein alpha subunit from Cochliobolus heterostrophus involved in mating and appressorium formation. Fungal Genet. Biol. 26:19-32.

Kang, H. J., Sigler, L., Lee, J., Gibas, C. F. C., Yun, S. H. and Lee, Y. W. 2010. Xylogone ganodermophthora sp. nov., an ascomycetous pathogen causing yellow rot on cultivated mushroom Ganoderma lucidum in Korea. Mycologia 102:11671184.

Kim, H. K., Hong, S. G. and Lee, J. C. 1993. Development of cultivation method of Ganoderma lucidum using culture bottle. pp. 350-356. In: Research report of Chungnam Agricultural Research and Extension Service, Korea. (In Korean) 
Lee, J. K., Choi, G. J., Cho, K. Y., Oh, S. J. and Park, J. S. 1996. Xylogone sphaerospora, a new fungal pathogen of cultivated Ganoderma lucidum. Kor. J. Mycol. 24:246-254.

Lee, T., Han, Y. K., Kim, K. H., Yun, S. H. and Lee, Y. W. 2002. Tri13 and Tri7 determine deoxynivalenol and nivalenol producing chemotypes of Gibberella zeae. Appl. Environ. Microbiol. 68:2148-2154.

Oh, S. J. 1996. Incidence of yellow rot disease on Ganoderma lucidum Karst: Identification, epidemiology and control. Master Thesis. Gyeongsang National University. (In Korean)

Oh, S. J., Chun, C. S., Lee, J. K. and Kim, H. K. 1998. Occurrence and identification of the fungus causing yellow rot on Gano- derma lucidum. Kor. J. Mycol. 26:31-38. (In Korean)

Ramesh, B., Hiremath, P. C., Hegde, R. K. and Bhat, R. 1993. Inducing ascospore germination of Guignardia calami-causal agent of areca leaf blight. Karnataka J. Agri. Sci. 6:303-304.

Stone, J. K., Pinkerton, J. N. and Johnson, K. B. 1994. Axenic culture of Anisogramma anomala: evidence for self-inhibition of ascospore germination and colony growth. Mycologia 86:674-683.

Vannini, A., Paganini, R. and Anselmi, N. 1996. Factors affecting discharge and germination of ascospores of Hypoxylon mediterraneum (De Not.) Mill. Eur. J. For. Pathol. 26:12-24. 